\title{
Environmental variability drives phytoplankton assemblage persistence in a subtropical reservoir
}

\author{
FABIANA SCHNECK, ${ }^{1 \star}$ ALBANO SCHWARZBOLD,${ }^{1}$ SILVANA C. RODRIGUES ${ }^{1}$ AND \\ ADRIANO S. MELO ${ }^{2}$ \\ ${ }^{1}$ Departamento de Ecologia, Instituto de Biociências, Universidade Federal do Rio Grande do Sul, CP \\ 15007, CEP 91501-970, Porto Alegre, RS, Brazil (Email: fabiana.schneck@gmail.com), and \\ ${ }^{2}$ Department of Ecologia, Instituto de Ciências Biológicas, Universidade Federal de Goiás, Goiânia, GO, \\ Brazil
}

\begin{abstract}
Temporal changes of assemblages may result from environmental variability and reflect seasonal dynamics of their ecosystem. In the subtropics, the hydrological regime is usually characterized by well-defined wet and dry seasons, regulating discharge and influencing a series of environmental variables that affect phytoplankton persistence. Therefore, we may expect that dry seasons are environmentally more stable than wet seasons. We analysed interannual phytoplankton assemblage variability (or, inversely, persistence) in a subtropical reservoir sampled every austral summer and winter during 5 years. We tested (i) if phytoplankton assemblage structure differed between the dry (summer) and wet (winter) seasons; (ii) if assemblage persistence differed between the seasons; (iii) if assemblage persistence was related to environmental stability; and (iv) if assemblage dissimilarity increased over time. Phytoplankton assemblages differed between the summer and winter seasons. Winter indicator species were mostly Bacillariophyceae or Cryptophyceae, whereas Cyanophyceae and Chlorophyceae taxa were more frequent and abundant in summer. Assemblages in the dry season were more persistent among years than those occurring during rainy periods. Similarly, environmental variability tended to be lower among dry than among rainy seasons. The relation between the phytoplankton temporal cycle and the temporal patterns of environmental variability supports our prediction that high environmental stability results in more persistent assemblages. Assemblage dissimilarity increased as sampling years were farther apart, for both seasons. Additionally, assemblages in the rainy periods showed a more pronounced increase in dissimilarity, as their changes among years were less predictable. We found a clear temporal pattern and an increased dissimilarity over time in the phytoplankton assemblage structure. Unravelling these temporal patterns may improve our understanding of phytoplankton temporal dynamics, and may have implications for management and monitoring programs. High dissimilarity of assemblages among years, particularly among rainy periods, can obscure human impacts, and monitoring programs should take this into account.
\end{abstract}

Key words: algae, interannual variability, plankton, seasonality, temporal stability.

\section{INTRODUCTION}

Temporal changes of assemblages are a central issue in ecology, and the understanding of the causes and consequences of these changes has long demanded the attention of ecologists. According to Bengtsson et al. (1997), all assemblages are temporally dynamic, and the degree of variability (or conversely, persistence) depends on physical and chemical characteristics of the habitat, its temporal stability, and on species interactions. Here, we use the term persistence following Rahel (1990) to refer to assemblage persistence, described by the constancy in absolute abundance, abundance ranking, or the presence or absence of species over time.

${ }^{\star}$ Corresponding author.

Accepted for publication December 2010.
Some studies have shown that high persistence is related to high environmental stability (but see Scarsbrook 2002). For instance, Oberdorff et al. (2001) found high fish persistence in rivers with more stable environmental conditions (i.e. discharge). Similarly, persistence of macroinvertebrates was low in streams where environmental conditions fluctuate or were characterized by pulses or stochastic disturbance events (Lake 2000). Furthermore, environmental variability usually increases through time (Steele 1985; Halley 1996), so that assemblages will show increased dissimilarity over long time intervals (Bengtsson et al. 1997). Several underlying processes may explain the increased assemblage dissimilarity through time. It may result from local extinction and colonization events, as different populations may respond differently to environmental fluctuations. Also, sampling 
effects may explain assemblage dissimilarity over time. If in each time interval the assemblage sampled is a random sample of the total species pool, then rare species or species that have emigrated or are in a dormant stage may not be sampled on one occasion, but may be sampled on other occasions, increasing the dissimilarity among samples over time.

Phytoplankton assemblages may show repeatable patterns from one year to another (i.e. interannual cycles), because, as stated by Rahel (1990), phytoplankton assemblages that fluctuate stochastically at short time scales (i.e. weeks), when viewed over long time intervals may show cyclical patterns of change and, consequently, be more stable than would appear from short-term sampling. Such cyclical patterns of phytoplankton assemblages likely reflect the seasonal dynamics of their environment. Annual patterns of phytoplankton seasonality in temperate areas are well established as mostly related to changes in light regime and water temperature; while in the tropics and subtropics, phytoplankton seasonality seems to be more influenced by hydrological characteristics (Pollingher 1986; Talling 1986; Chellappa et al. 2009).

The hydrological regime in the tropics and subtropics is usually characterized by well-defined wet and dry seasons. This hydrological cycle regulates discharge and influences a series of other environmental variables that affect phytoplankton assemblages, such as water turbidity, nutrient supply and water temperature. High discharge may disrupt assemblage structure, leading to low assemblage persistence. Furthermore, the hydrological regime also greatly influences phytoplankton assemblages in reservoirs, as precipitation governs dam operation and water retention times, producing pulses of material and nutrients in suspension, material cycling and biomass loss (Calijuri et al. 2002).

Long-term studies on tropical and subtropical freshwater phytoplankton are important to the understanding of the temporal dynamics of assemblages and may have implications for management and monitoring programmes, especially in reservoirs. A snapshot sample may not be enough to infer main processes governing assemblage structure (Nabout et al. 2009). For instance, high seasonal or interannual changes in an assemblage could be misinterpreted as caused by human impacts, with implications for management and conservation efforts (Espírito-Santo et al. 2009). On the other hand, if an assemblage changes randomly among seasons or years, our predictive ability would be low, and so would our ability to assess human impacts on the assemblage (Cottingham \& Carpenter 1998; Espírito-Santo et al. 2009).

We studied freshwater phytoplankton in a subtropical reservoir sampled every austral summer (dry) and winter (rainy) during 5 years. We tested: (i) if the phytoplankton assemblage structure differed between summers and winters; (ii) if the assemblage persis- tence differed between seasons and (iii) if it was related to environmental stability; and (iv) if assemblage dissimilarity increased with time. We expected that assemblage structure would differ between seasons, and that the season with high environmental variability would show high assemblage variability. Also, we predicted that assemblage dissimilarities would increase as the sampled years become farther apart, as a result of increased environmental and population variability over time (Bengtsson et al. 1997). Although this increase in dissimilarity over time should occur for both summer and winter assemblages, we expected it to be more pronounced in the season with higher environmental variability.

\section{METHODS}

\section{Study area and sampling}

Dona Francisca Hydroelectric Reservoir is located on the Jacuí River $\left(29^{\circ} 20^{\prime} \mathrm{S}, 53^{\circ} 12^{\prime} \mathrm{W}\right)$, Rio Grande do Sul State, southern Brazil (Fig. 1), the farthest downstream of three cascade reservoirs. The reservoir, dammed in 2000, comprises $19 \mathrm{~km}^{2}$ with a drainage area of $13200 \mathrm{~km}^{2}$ and a volume of $0.335 \mathrm{~km}^{3}$. The reservoir has low water retention time, usually around 15 days, and is predominantly mesotrophic and warm-monomictic with a period of summer stratification (Rodrigues 2002).

Samples were obtained during austral summer (December, January or February) and winter (June or August) from 2005 to 2010. Summer samples were available for 20052008 and 2010, and winter samples were obtained uninterruptedly in the period 2005-2009, all of them at four sites located along the reservoir (Fig. 1). Rainfall (measured during the 30 days before samplings) differed between summer and winter, with higher precipitation in winters (mean of $186 \mathrm{~mm}$ per month) than in summers (mean of $97 \mathrm{~mm}$ per month).

Phytoplankton samples were taken in surface waters using $1-\mathrm{L}$ bottles and preserved with $1 \%$ Lugol's solution in the dark. Phytoplankton samples were counted using an inverted microscope (Utermöhl 1958). Every cell, filament or colony was considered one individual, and the number of individuals counted in each sample was determined following two criteria: the attainment of an asymptote in the species accumulation curve and a counting efficiency of $90 \%$, according to Pappas and Stoermer (1996). At least 50 random fields and 100 individuals were counted per sample (APHA 1998), with a total of 10287 individuals counted.

Physical and chemical data were gathered concomitantly with the phytoplankton samples. Electrical conductivity, $\mathrm{pH}$ and water temperature were obtained by portable digital potentiometers. Water transparency was measured with a Secchi disc. The determination of dissolved oxygen (azide modification method), biochemical oxygen demand (azide modification method), nitrate (ultraviolet spectrophotometric screening method) and total phosphorus (stannous chloride method) followed standardized procedures (APHA 1998) (Table 1). 


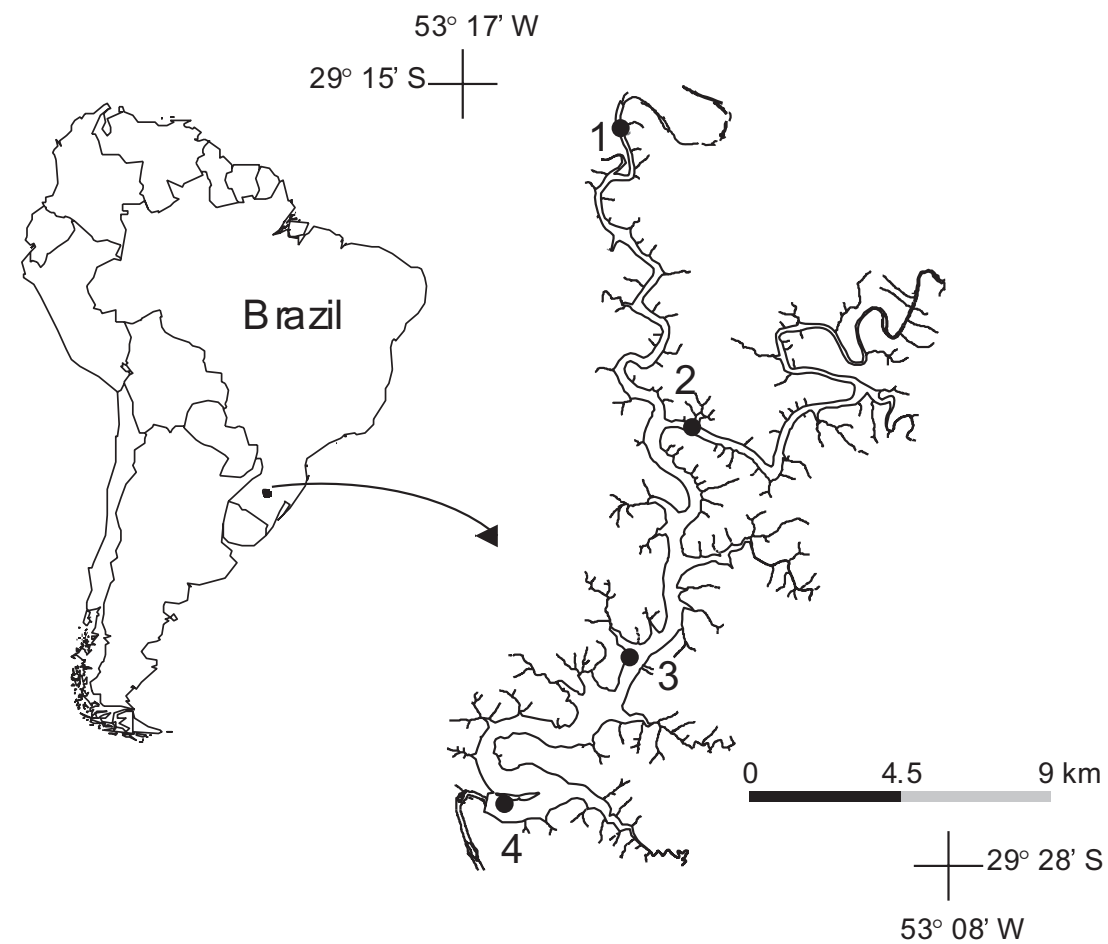

Fig. 1. Location of Dona Francisca Reservoir in southern Brazil, and the four sampling sites (black circles and numbers).

Table 1. Mean \pm standard deviation and coefficient of variation in parentheses (\%) of environmental variables during austral summers and winters in Dona Francisca Reservoir (Rio Grande do Sul, Brazil), from the years 2005 to 2010

\begin{tabular}{lcc}
\hline Environmental variables & Summer & Winter \\
\hline Oxygen saturation $\left(\% \mathrm{O}_{2}\right)$ & $106.5 \pm 24.0(22.5)$ & $84.5 \pm 9.8(11.6)$ \\
Biochemical oxygen demand $\left(\mathrm{mg} \mathrm{L}^{-1}\right)$ & $2.66 \pm 1.84(68.9)$ & $0.93 \pm 1.12(120.9)$ \\
Conductivity $\left(\mu \mathrm{S} \mathrm{cm}^{-1}\right)$ & $45.14 \pm 3.07(6.80)$ & $44.45 \pm 3.00(6.75)$ \\
$\mathrm{pH}$ & $7.6 \pm 0.9(12.0)$ & $7.2 \pm 0.3(4.4)$ \\
Nitrate $\left(\mathrm{mg} \mathrm{L}^{-1}\right)$ & $0.584 \pm 0.351(60.2)$ & $0.663 \pm 0.485(73.1)$ \\
Total phosphorus $\left(\mathrm{mg} \mathrm{L}^{-1}\right)$ & $0.059 \pm 0.026(44.5)$ & $0.064 \pm 0.048(75.1)$ \\
Water temperature $\left({ }^{\circ} \mathrm{C}\right)$ & $26.5 \pm 3.4(12.6)$ & $15.3 \pm 2.8(18.3)$ \\
Secchi depth $(\mathrm{cm})$ & $140.6 \pm 54.2(38.5)$ & $123.9 \pm 75.8(61.2)$ \\
\hline
\end{tabular}

\section{Data analyses}

In order to evaluate whether the summer and winter assemblages were distinct, we used distance-based multivariate analysis of variance (db-MANOvA; Anderson 2001) with 9999 permutations stratified within the four sites, thus accounting for spatial and environmental effects. The analysis was based on a dissimilarity matrix obtained with the Bray-Curtis index (Faith et al. 1987; Legendre \& Legendre 1998) applied to transformed $\log (x+1)$ density data. Additionally, we identified species associated with each season using the Indicator Species Analysis (Dufrêne \& Legendre 1997). The analysis was applied to the density matrix, including all species, and using seasons (summer and winter) as the grouping variables.

We performed a permutation test for homogeneity of multivariate dispersions among the sample units (i.e. samples collected each summer and winter during 5 years at four sites) to test for differences in assemblage persistence between summer and winter (Anderson 2006). The test is based on the distances from individual points (samples) to their group centroid in the full dimensional space calculated in a Principal Coordinates Analysis (PCoA). We used the same dissimilarity matrix employed in the db-MANOva and ran 9999 permutations stratified within sites. As the use of non-metric dissimilarity coefficients produced principal coordinates axes with negative eigenvalues, we computed the square root of distances and reran the analysis to prevent this (Legendre \& Legendre 1998). The ordination diagrams are presented both for all four sites together and for each site separately to better visualize the dispersion of the experimental units.

To evaluate if assemblage persistence is related to environmental stability, we generated several Euclidean distance matrices composed of all possible combinations of subsets of 
Table 2. Results of the BioEnv analysis for samples collected in four sampling sites in Dona Francisca Reservoir (Rio Grande do Sul, Brazil), from the years 2005 to 2010

\begin{tabular}{llc}
\hline Model size & \multicolumn{1}{c}{ Model } & Correlation \\
\hline 1 & TP & 0.4528 \\
2 & temp + TP & 0.4931 \\
3 & temp + TP + nitrate & 0.4937 \\
4 & temp + TP + nitrate + secchi & 0.4774 \\
5 & cond + temp + TP + nitrate + secchi & 0.4679 \\
6 & cond + temp + TP + nitrate + BOD + secchi & 0.4410 \\
7 & cond + temp + TP + nitrate $+\% \mathrm{O}_{2}+\mathrm{BOD}+$ secchi & 0.3676 \\
8 & cond + temp + TP + nitrate $+\% \mathrm{O}_{2}+\mathrm{pH}+\mathrm{BOD}+$ secchi & 0.3179 \\
\hline
\end{tabular}

Samples obtained during summer and winter were pooled for the analysis. Spearman correlation for the best model is shown in bold. $\% \mathrm{O}_{2}$, oxygen saturation; $\mathrm{BOD}$, biochemical oxygen demand; cond, conductivity; secchi, Secchi depth; temp, water temperature; TP, total phosphorus.

environmental variables, and selected the subset with maximum Spearman's rank correlation with the biotic dissimilarity matrix (Bray-Curtis index, $\log (x+1)$ data) (BioEnv approach; Clarke \& Ainsworth 1993). Euclidean distances were calculated after centring each variable by its mean and scaling each variable by its standard deviation. The selected variables were water temperature, total phosphorus, and nitrate $(r=0.49$; Tables 1,2$)$. The BioEnv approach was applied to all samples irrespective of sampling season. We conducted two permutation tests for homogeneity of multivariate dispersions among the sample units to test for differences in environmental stability between summer and winter (Anderson 2006). The first one was done for the Euclidean distance matrix selected using the BioEnv approach. The second one used the Euclidean distance matrix generated using all environmental variables.

Measures of assemblage persistence may be influenced by rare species; some investigators argue that they represent a source of noise in analyses and thus prevent the detection of patterns of assemblage structure (see Marchant 1999). Accordingly, many studies have not included them in the analyses (e.g. Anneville et al. 2004; Soininen et al. 2005; Bovo-Scomparin \& Train 2008). We assessed this potential effect, and performed analyses both with the complete dataset and with only abundant species (at least 5\% abundance in one sample). The same pattern was obtained, and we opted to show results only from analyses including the full dataset.

Our hypothesis that assemblage dissimilarity increases with temporal distance between the observations was evaluated using Mantel tests with Pearson's correlation and 9999 permutations stratified within sites, separately for summer and winter samples. We used a biotic Bray-Curtis dissimilarity matrix $(\log (x+1))$ as our first matrix, and a Euclidean distance matrix among years as our second matrix (i.e. number of years apart). Additionally, we conducted a linear regression between the biotic dissimilarity matrices and the 'years apart' matrices to obtain the regression coefficients (b) of each analysis, and thus compare the slopes obtained for summer and winter assemblages as an indicator of the rate of temporal dissimilarity (Korhonen et al. 2010). According to Korhonen et al. (2010), although the pairwise comparison of data inflates the number of observations in the regression, the estimate of the regression coefficients is not inflated. The same analyses (Mantel tests and linear regressions) were conducted for the environmental variables using both the Euclidean distance matrix selected by the BioEnv approach and the Euclidean distance matrix generated using all environmental variables.

We used species densities instead of species biovolume or functional groups in all analyses. We followed the study by Carneiro et al. (2010) in which they evaluated the influence of taxonomic and numerical resolution on the analysis of temporal changes in phytoplankton assemblages in streams and concluded that ordinations generated using species densities were similar to those generated using biovolume. They also found that ordination patterns based on functional groups matched those based on genera or families. However, as discussed by Carneiro et al. (2010), the use of distinct taxonomical and numerical resolution is not an easy issue and needs to be carefully evaluated, because assemblage organization patterns (e.g. occurrence of few or many dominant species, number of species per genera) and algal physiological processes related to cell volumes may vary among different aquatic systems.

We conducted all analyses using the $\mathrm{R}$ environment (The $\mathrm{R}$ Development Core Team 2009). The db-MANova, the test of multivariate dispersions, the BioEnv analysis and the Mantel tests were calculated using the vegan package (Oksanen et al. 2010), and the Indicator Species Analysis using the labdsv package (Roberts 2010).

\section{RESULTS}

A total of 336 taxa were identified. The most speciesrich groups were Chlorophyceae (37.5\%), Bacillariophyceae (26.2\%), Zygnematophyceae (10.1\%) and Cyanobacteria (8.9\%). Summer samples included 272 taxa in the 5 years evaluated, 89 of which were exclusive to this season. Samples obtained in the five winters included 247 species, 64 of which did not occur in the summer samples. Chlorophyceae and Bacillariophyceae accounted for approximately $65 \%$ of the total density in both seasons. Cyanobacteria density was high in the summer samples, comprising $11 \%$ of 

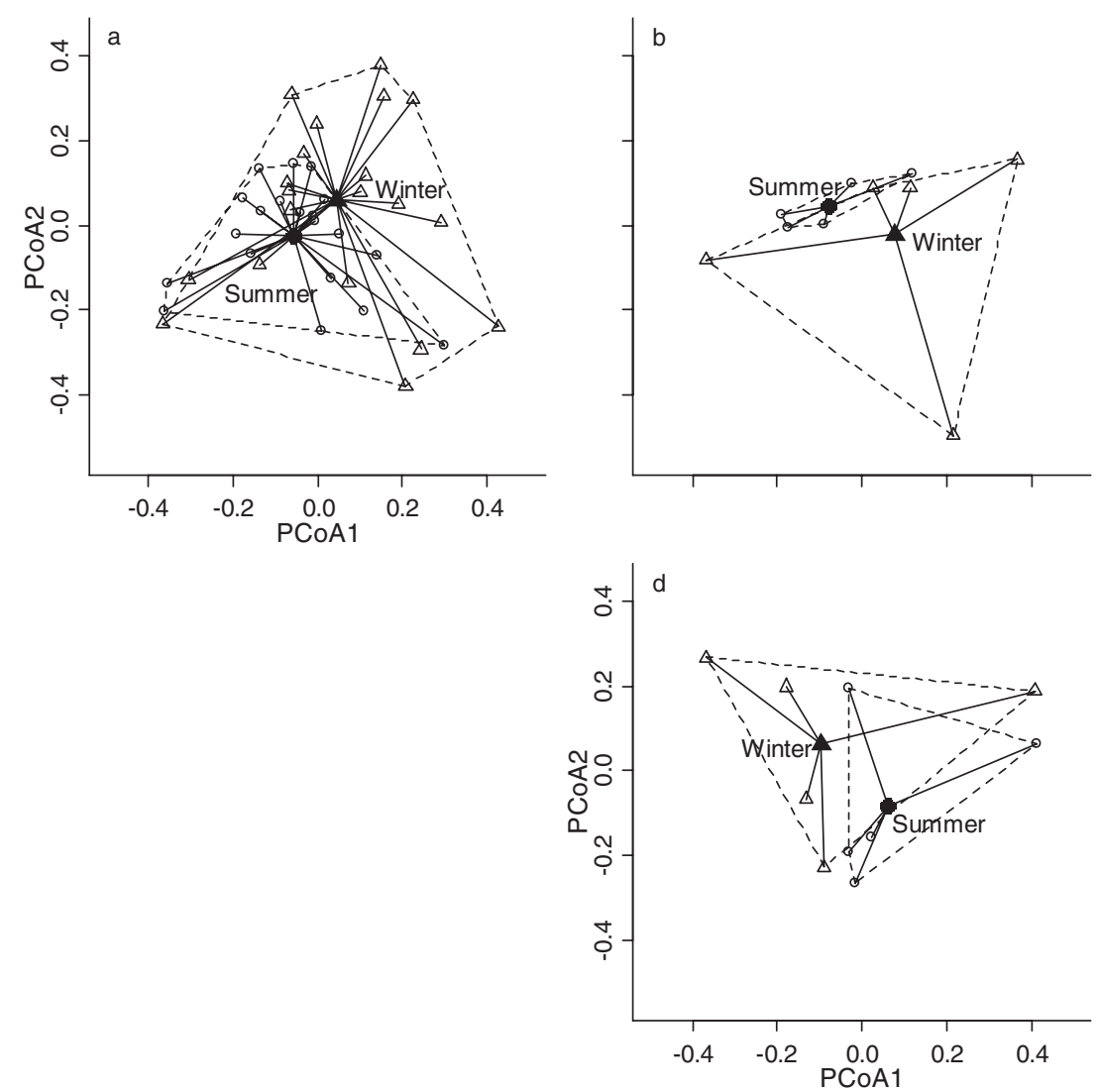
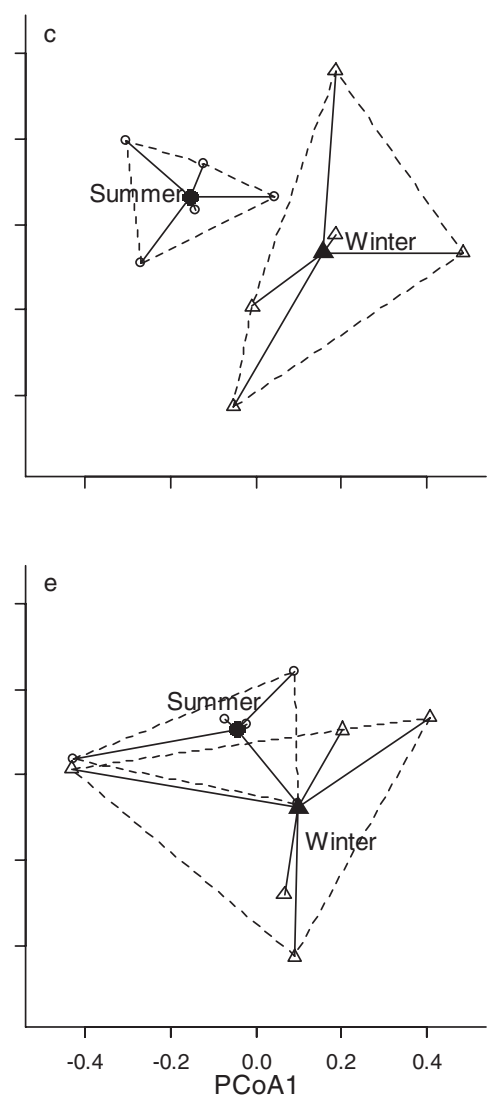

Fig. 2. Principal Coordinates Analysis (PCoA) of phytoplankton sampling units obtained for all four sites together (a) and each site separately (b-e; sites 1 to 4, respectively, as shown in Fig. 1) in the Dona Francisca Reservoir (Rio Grande do Sul, Brazil) during austral summers and winters in the period 2005-2010. The differences in dispersions to the group centroid for summer and winter samples are interpretable as differences in community structure among years within each season. Open circles indicate PCoA scores for summer samples, and open triangles indicate winter samples. Polygons indicate maximum dispersion of units for each season. The solid circle and triangle in the centre of each polygon represent the respective group centroids.

the individuals, whereas this group comprised less than $3 \%$ of winter total individuals. In contrast, Cryptophyceae occurred mostly in the winter, accounting for $7.5 \%$ of the total individuals in this season. In summer, the class contributed $0.14 \%$ of the individuals.

Assemblages were significantly different between seasons (db-MANOVA; $\left.F_{1,38}=2.35 ; P<0.001\right)$. The Indicator Species Analysis revealed that 13 taxa were significantly $(P<0.05)$ associated with summer: Chlorella vulgaris Beij., Dictyosphaerium pulchellum Wood, Merismopedia tenuissima Lemm., Chrysococcus sp1, Monoraphidium sp1, Scenedesmus sp1, Kephyrion sp1, Cyclotella sp1, Cyclotella sp2, Anabaena spiroides Kleb., Schroederia setigera (Schröd.) Lemm., Chlamydomonas sp1 and Peridinium sp2. Eight taxa were associated with winter: Aulacoseira ambigua (Grun.) Sim. f. spiralis Ludw., Aulacoseira granulata (Ehr.) Sim. var. angustissima (O. Müller) Sim., Cryptomonas phaseolus Skuja, Pediastrum tetras (Ehr.) Ralfs, Nitzschia sp1, Cryptomonas erosa Ehr., Cryptomonas ovata Ehr. and Pinnularia sp1.
The PCoA plot showed that the summer sample units were less dispersed in multivariate space than were the winter units, both for all four sites together and for each site separately (Fig. 2). Indeed, group dispersions differed significantly (tested only for all sites together using permutations stratified within sites), and summer (dry) assemblages were less variable (i.e. more persistent) among years than winter (rainy) assemblages (permutation test for homogeneity of multivariate dispersions; $F_{1,38}=2.62 ; P=0.043$ ). We also found that environmental variability was greater among winters than among summers for the environmental distance matrix selected by BioEnv (permutation test for homogeneity of multivariate dispersions; $F_{1,38}=6.34 ; P=0.008$; Fig. 3a). However, group dispersions did not differ significantly for the distance matrix generated using the whole environmental matrix (permutation test for homogeneity of multivariate dispersions; $F_{1,38}=0.01 ; P=0.903$; Fig. $3 b$ ).

Our hypothesis that assemblage dissimilarity increases with temporal distance between the observations was confirmed. Assemblage dissimilarities 

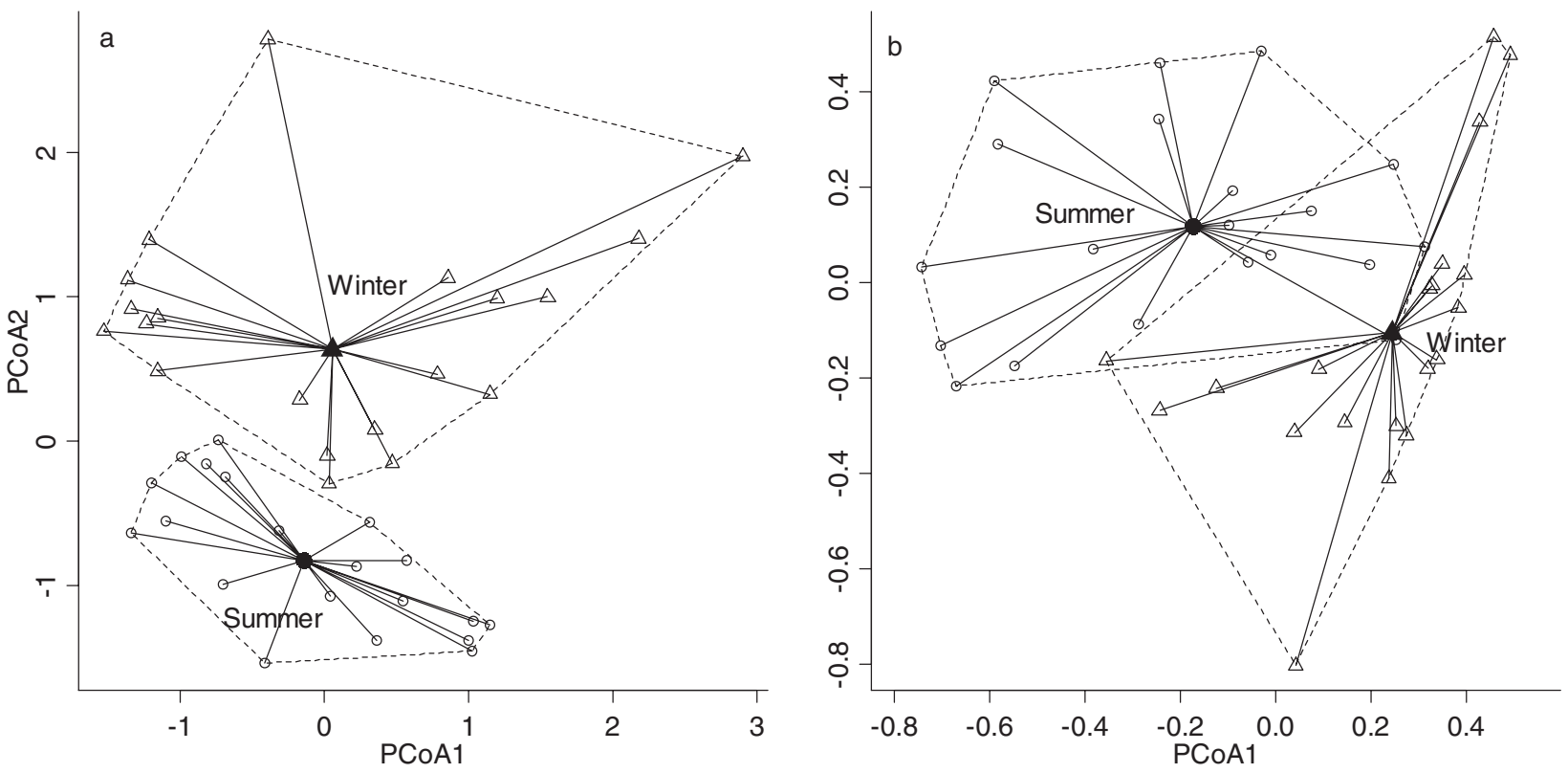

Fig. 3. Principal Coordinates Analysis ( $\mathrm{PCoA})$ of environmental sampling units using the distance matrix selected by the BioEnv approach (a; see Table 2 for the model) and using all environmental variables (b) obtained for all four sites together in the Dona Francisca Reservoir (Rio Grande do Sul, Brazil) during austral summers and winters in the period 2005-2010. See Figure 2 for symbol legends.

increased as the sampled years were farther apart for both summer (Mantel test: $r=0.45 ; P<0.001$ ) and winter (Mantel test: $r=0.36 ; P<0.001$ ). Additionally, the regression coefficient for summer was slightly lower $(b=0.035)$ than in the winter (rainy) assemblages $(b=0.040)$ (Fig. 4a), providing additional support to the view that summer assemblages are more persistent over time than winter assemblages. We also found an increased environmental variability over time for both summer and winter, using either the environmental distance matrix selected by BioEnv (Mantel test; summer: $r=0.44, P<0.001$; winter: $r=0.28$, $P=0.006)$ or the distance matrix generated using all environmental variables (Mantel test; summer: $r=0.43, P<0.001$; winter: $r=0.29, \quad P<0.001$ ). However, the regression coefficients were higher for summer than for winter for both the distance matrix selected by BioEnv ( $b$ for summer $=0.390 ; b$ for winter $=0.246$; Fig. $4 \mathrm{~b}$ ) and the distance matrix generated using all environmental variables ( $b$ for summer $=0.448 ; b$ for winter $=0.323$; Fig. $4 \mathrm{c}$ ).

\section{DISCUSSION}

Our results showed that the phytoplankton assemblage differed between the summer and winter seasons, and also that the summer (dry season) assemblage was more persistent among years than the winter (wet season) assemblage. We found that environmental variability tended to be higher during winter than summer, and this finding offers support to our hypothesis that low environmental variability in summer results in high persistence of assemblages. Additionally, assemblage dissimilarity increased as sampling years were farther apart, for both the summer and winter assemblages.

Phytoplankton assemblage differentiation between summer and winter was pronounced and probably related to the species' capabilities to deal with changing environmental features. Merismopedia tenuissima and Anabaena spiroides, the two Cyanobacteria selected as indicator species for summer, showed in that season densities more than 20 times greater than in winters. This result may be associated with an increased water retention time that is directly related to the lower precipitation in summer, as many species of Cyanobacteria are sensitive to high discharge and tend to form blooms in reservoirs with long retention times (Harris \& Baxter 1996; Rodrigues et al. 2009). Chlorella vulgaris and Monoraphidium sp1, whose genera are described as tolerating water stratification (Reynolds et al. 2002), showed higher densities and frequencies during summer, the period of water stratification in the reservoir (Rodrigues 2002). Colonial Chlorophyceae, such as Dictyosphaerium pulchellum, are related to habitats with high luminosity and low nutrient concentrations, while the Dinophyceae Peridinium is suggested to be sensitive to mixing periods (Reynolds et al. 2002). Some other indicator species for summer, like Cyclotella spp., are expected to occur preferentially on mixed waters (Lopes et al. 2005). 

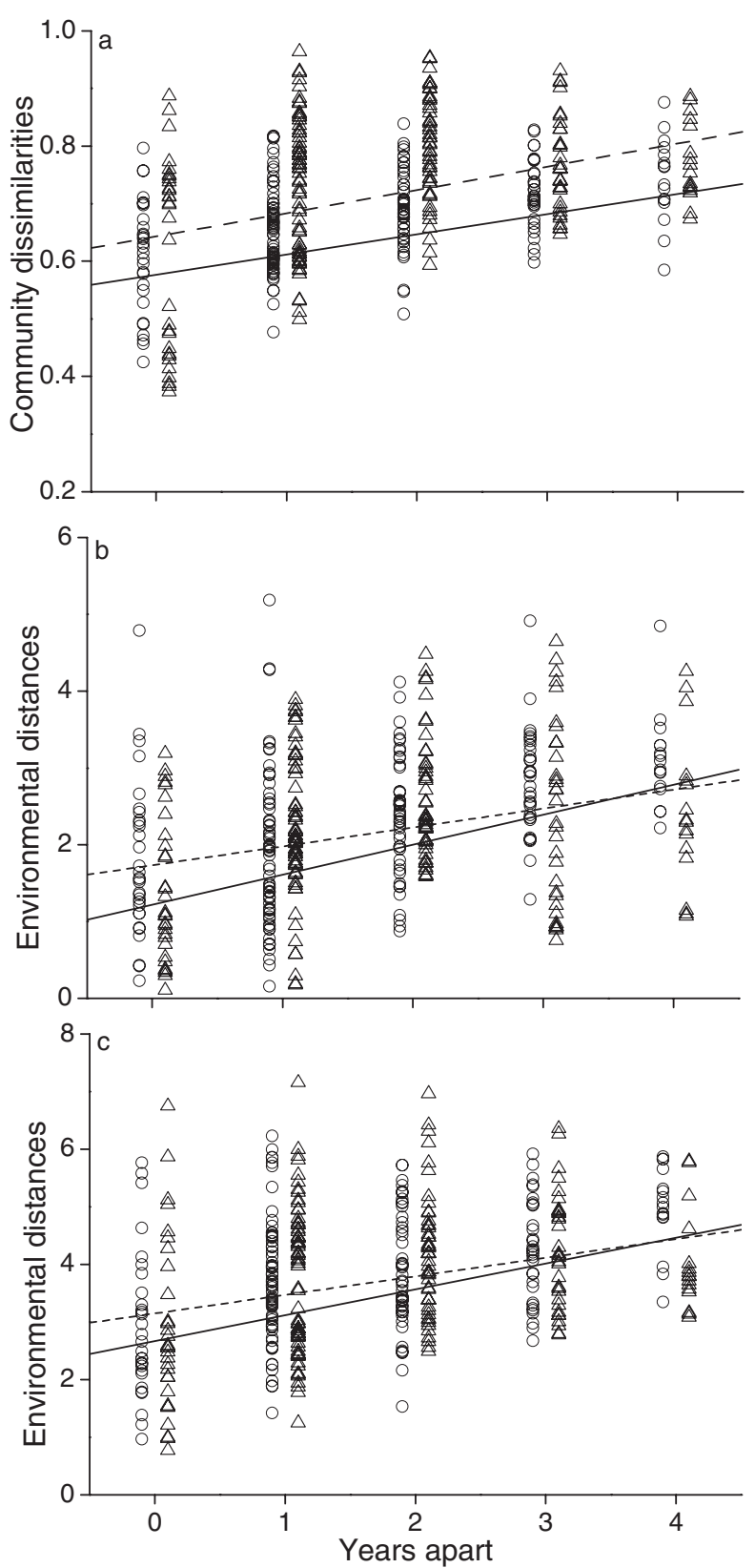

Fig. 4. Bray-Curtis dissimilarities between phytoplankton assemblages in relation to years apart (a) and Euclidean distances between environmental variables in relation to years apart for the distance matrix selected by the BioEnv approach (b) and for the distance matrix obtained using all environmental variables (c), during austral summers and winters in the period 2005-2010. Data were obtained at four sites in the Dona Francisca Reservoir (Rio Grande do Sul, Brazil). Circles indicate dissimilarities for summer samples, and triangles indicate winter samples. The solid and dashed lines are the linear regressions for summer and winter samples, respectively. Symbols for both seasons are dislocated to prevent overlap.
Indicator species for the rainy (winter) period were mostly Bacillariophyceae and Cryptophyceae. Borges et al. (2008) studied two subtropical Brazilian reservoirs, and observed that densities of Cryptophyceae and Bacillariophyceae species, mainly $A$. granulata, $A$. ambigua and Cryptomonas spp., were positively associated with highly hydrodynamic environments, which favour nanoplanktonic species with high reproductive rates. Further, interannual studies on phytoplankton variability in subtropical reservoirs and lakes found that $A$. gramulata, A. ambigua and Cryptomonas spp. were dominant in periods of high precipitation and, consequently, high outflow (Harris \& Baxter 1996; Bovo-Scomparin \& Train 2008). Rodrigues et al. (2009) observed that the population of A. granulata decreased in less hydrodynamic environments, as the species depends on turbulence for suspension. Similarly, A. ambigua is considered sensitive to stratification and occurs preferentially in conditions of total water column mixing (Reynolds et al. 2002). Cryptomonas species are very opportunistic, tolerant to high turbulence and low luminosity, and are highly associated with periods of water mixing (Klaveness 1988; Jones 2000; Borges et al. 2008). Our results confirm the influence of climatic variability on the seasonal variation of the assemblage, in that the above-mentioned Bacillariophyceae and Cryptophyceae species were indicators of the rainiest period, when environmental hydrodynamics in the reservoir are pronounced.

The phytoplankton assemblage followed a welldefined temporal trend during the 5 years of the study. The assemblage was less variable among summers, when the study area receives low rainfall. Assemblages seem to follow a single base of attraction in this season, contrasting with assemblages in winters, which showed higher variability. The relationship of the phytoplankton temporal variability with the environmental variability was dependent on the environmental data used to conduct the test for homogeneity of multivariate dispersions. The environmental variables selected by the BioEnv approach (water temperature, total phosphorus and nitrate) showed a greater dispersion among winters than among summers, similar to the results of the phytoplankton temporal variability. However, the environmental temporal variability did not differ between summer and winter for the whole environmental matrix. The use of all the environmental variables may have prevented the detection of temporal patterns, as some variables may not be correlated with the phytoplankton assemblage and thus may override the effects of variables related to the assemblage. For instance, the two variables with highest coefficients of variation among summers (oxygen saturation and $\mathrm{pH}$ ) appear only in the two worst models of the BioEnv analysis (Table 2), indicating that these 
variables are not highly correlated with the biotic matrix and that their variation may not have a significant effect on the assemblage. In this sense, we concluded that environmental variability was better predicted by the variables selected by the BioEnv analysis and that the phytoplankton temporal variability was closely related to the temporal patterns of environmental variability, supporting our prediction that high environmental stability results in more persistent assemblages.

Previous interannual studies on phytoplankton assemblages have reported that distinct species composition and abundance may characterize assemblages in different seasons or different environmental conditions (Harris \& Baxter 1996; Anneville et al. 2004; Bovo-Scomparin \& Train 2008; Rodrigues et al. 2009). However, little is known about whether phytoplankton temporal assemblage persistence is directly and positively related to environmental stability. Our results contrast with those obtained by Soininen et al. (2005) in the study of a boreal lake. They did not find a relationship between environmental variability of the lake and the corresponding variability of its phytoplankton assemblage structure over 5 years. Moreover, the same authors observed that phytoplankton assemblage did not show a temporal trend, thus concluding that the assemblage was unpredictable through the years. In contrast, our results were similar to those of Townsend et al. (1987), who found high persistence in stream macroinvertebrate assemblages at sites with high environmental stability (lower ranges of temperature, $\mathrm{pH}$ and discharge).

The relationship between environmental stability and assemblage persistence suggests that species composition and abundance could be determined by different responses to environmental changes, independent of biological interactions (Oberdorff et al. 2001). According to Naselli-Flores et al. (2003), mixed lakes are fast-changing ecosystems characterized by rapid and unpredictable phytoplankton changes. In our study, higher environmental variability among winters, when rainfall is high and the reservoir has water-mixing periods, may result in an unstable environment (high coefficient of variation of nutrients and temperature conditions, the environmental variables selected by the BioEnv approach) that could be harsh for some species, disrupting assemblage structure and leading to low assemblage persistence. On the other hand, summers were characterized by low environmental variability; thus, the major forces driving the persistence of the phytoplankton assemblage were related to the lack of disturbances and their consequences, such as thermal stratification. Similarly, Harris and Baxter (1996) studied a subtropical reservoir in Australia during 16 years and observed that the pattern of temporal variability in phytoplankton species abundances was related to reservoir seasonal stratification, alternating from stratified periods during summers to mixed periods during winters.

Our results are in agreement with the criteria of Connell and Souza (1983) for considering an assemblage as persistent. The authors pointed out that a persistent assemblage is one that remains in the same state or that returns to the original state when disturbance ceases. Indeed, we showed that the phytoplankton assemblage seems to be pulled by a single attractor state in summers, resulting in high assemblage persistence over the years. Furthermore, according to Connell and Souza (1983), at least one complete turnover of all individuals should be reached when studying persistence of assemblages. The 5-year period of our study exceeds 200 generation times of most species, as phytoplankton species have generation times ranging from hours to few days.

We expected a higher increase in dissimilarity over time for the rainy winter assemblages than for summer assemblages, as winter assemblages were characterized by unpredictable changes among years. Our results showed that assemblage dissimilarity increased over time for both seasons, and that the slope of the regression for summer was smaller than for winter, indicating that temporal dissimilarity was less intense for summer assemblages than for winter assemblages over a similar period. This result is in accordance with the test for homogeneity of dispersions, indicating greater persistence among summer assemblages than among winter assemblages. The different patterns observed in the slopes for the environmental variables (i.e. the regression coefficient for summer was higher than that for winter) may result from the high variation among winters at the short year-to-year temporal scale. At longer time scales, however, previous environmental conditions are repeated, and thus the overall trend is for low increase in variability. Supporting evidence for this interpretation is the low coefficient of correlation from the Mantel test in the rainy winter, indicating high year-to-year variability. In agreement with our results of increased assemblage dissimilarity over time, Bêche and Resh (2007) found that the magnitude of directional changes in macroinvertebrate assemblages over time was dependent on environmental conditions, with a greater increase in assemblage dissimilarity (i.e. steeper slopes) occurring in streams that experienced greater flow and shear stress caused by precipitation.

Our result of increased assemblage and environmental dissimilarity over time is in accordance with the study of Korhonen et al. (2010), who evaluated the distance decay of similarity in time in a metaanalysis of aquatic ecosystems. Korhonen et al. (2010) suggested that ecological patterns may show 
predictable variability through time, and that assemblage temporal turnover may be affected by processes driven by environmental variability over time or by patterns of dispersal across sites. Accordingly, Bengtsson et al. (1997) stated that environmental variability through time might result in increased population dissimilarity if different species show different responses to changes in the environment and, consequently, increased assemblage dissimilarity over time should be expected.

We found that the phytoplankton showed distinct assemblage structures between seasons, with higher persistence among summers than among rainy winters, and that dissimilarity increased over longer periods. Accordingly, we conclude that natural variability between seasons and among years should be taken into account in studies assessing human impacts. Little can be inferred about the processes structuring an assemblage if only a 'snapshot' of the community is taken. Moreover, accounting for these temporal patterns may improve our ability to decide the appropriate management options and conservation efforts, as we could disentangle the effects of natural assemblage variability from those caused by anthropogenic disturbances.

\section{ACKNOWLEDGEMENTS}

We thank Dona Francisca Eletricidade (DFESA) for the available data. LM Bini provided detailed suggestions that improved the manuscript. Janet Reid reviewed the English. F Schneck received a student fellowship from Coordenação de Aperfeiçoamento de Pessoal de Nível Superior (CAPES). AS Melo received a research grant and a research fellowship from Conselho Nacional de Desenvolvimento Científico e Tecnológico (CNPq 476304/2007-5; 302482/2008-3), and a research grant from the International Foundation for Science (IFS no. A/4107-1).

\section{REFERENCES}

American Public Health Association (APHA) (1998) Standard Methods for the Examination of Water and Wastewater. APHA, Washington DC.

Anderson M. J. (2001) A new method for non-parametric multivariate analysis of variance. Austral Ecol. 26, 32-46.

Anderson M. J. (2006) Distance-based tests for homogeneity of multivariate dispersions. Biometrics 62, 245-53.

Anneville O., Souissi S., Gammeter S. \& Straile D. (2004) Seasonal and inter-annual scales of variability in phytoplankton assemblages: comparison of phytoplankton dynamics in three peri-alpine lakes over a period of 28 years. Freshw. Biol. 49, 98-115.
Bêche L. A. \& Resh V. H. (2007) Short-term climatic trends affect the temporal variability of macroinvertebrates in California 'Mediterranean' streams. Freshw. Biol. 52, 2317-39.

Bengtsson J., Baillie S. R. \& Lawton J. (1997) Community variability increases with time. Oikos 78, 249-56.

Borges P. A. F., Train S. \& Rodrigues L. C. (2008) Spatial and temporal variation of phytoplankton in two subtropical reservoirs. Hydrobiologia 607, 63-74.

Bovo-Scomparin V. M. \& Train S. (2008) Long-term variability of the phytoplankton community in an isolated floodplain lake of the Ivinhema River State Park, Brazil. Hydrobiologia 610, 331-44.

Calijuri M. C., Santos A. C. A. \& Jati S. (2002) Temporal changes in the phytoplankton community structure in a tropical and eutrophic reservoir (Barra Bonita, S.P. Brazil). F. Plankton Res. 24, 617-34.

Carneiro F. M., Bini L. M. \& Rodrigues L. C. (2010) Influence of taxonomic and numerical resolution on the analysis of temporal changes in phytoplankton communities. Ecol. Indic. 10, 249-55.

Chellappa N. T., Chellappa T., Câmara F. R. A., Rocha O. \& Chellappa S. (2009) Impacts of stress and disturbance factors on the phytoplankton communities in Northeastern Brazil reservoir. Limnologica 39, 273-82.

Clarke K. R. \& Ainsworth M. (1993) A method of linking multivariate community structure to environmental variables. Mar Ecol.-Prog. Ser. 92, 205-19.

Connell J. H. \& Souza W. P. (1983) On the evidence needed to judge ecological stability or persistence. Am. Nat. 121, 789 824 .

Cottingham K. L. \& Carpenter S. R. (1998) Population, community, and ecosystem variates as ecological indicators: phytoplankton responses to whole-lake enrichment. Ecol. Appl. $8,508-30$.

Dufrêne M. \& Legendre P. (1997) Species assemblages and indicator species: the need for a flexible asymmetrical approach. Ecol. Monogr. 67, 345-66.

Espírito-Santo H. M. V., Magnusson W. E., Zuanon J., Mendonça F. P. \& Landeiro V. L. (2009) Seasonal variation in the composition of fish assemblages in small Amazonian forest streams: evidence for predictable changes. Freshw. Biol. 54, 536-48.

Faith D. P., Minchin P. R. \& Belbin L. (1987) Compositional dissimilarity as a robust measure of ecological distance. Vegetatio 69, 57-68.

Halley J. M. (1996) Ecology, evolution and 1/f-noise. Trends Ecol. Evol. 11, 33-7.

Harris G. P. \& Baxter G. (1996) Interannual variability in phytoplankton biomass and species composition in a subtropical reservoir. Freshw. Biol. 35, 545-60.

Jones R. I. (2000) Mixotrophy in planktonic protists: an overview. Freshw. Biol. 45, 219-26.

Klaveness D. (1988) Ecology of the Cryptomonadida: a first review. In: Growth and Reproductive Strategies of Freshwater Phytoplankton (ed. C. D. Sangren) pp. 103-33. Cambridge University Press, Cambridge.

Korhonen J. J., Soininen J. \& Hillebrand H. (2010) A quantitative analysis of temporal turnover in aquatic species assemblages across ecosystems. Ecology 91, 508-17.

Lake P. S. (2000) Disturbance, patchiness and diversity in streams. F. N. Am. Benthol. Soc. 19, 573-92.

Legendre P. \& Legendre L. (1998) Numerical Ecology. Elsevier, Amsterdam. 
Lopes M. R. M., Bicudo C. E. M. \& Ferragut C. (2005) Short term spatial and temporal variation of phytoplankton in a shallow tropical oligotrophic reservoir, southeast Brazil. Hydrobiologia 542, 235-47.

Marchant R. (1999) How important are rare species in aquatic community ecology and bioassessment? A comment on the conclusions of Cao et al. Limnol. Oceanogr. 44, 1840-1.

Nabout J. C., Siqueira T., Bini L. M. \& Nogueira I. S. (2009) No evidence for environmental and spatial processes in structuring phytoplankton communities. Acta Oecol. 35, 720-6.

Naselli-Flores L., Padisák J., Dokulil M. T. \& Chorus I. (2003) Equilibrium/steady-state concept in phytoplankton ecology. Hydrobiologia 502, 395-403.

Oberdorff T., Hugueny B. \& Vigneron T. (2001) Is assemblage variability related to environmental variability? An answer for riverine fish. Oikos 93, 419-28.

Oksanen J., Kindt R., Legendre P. et al. (2010) vegan: Community Ecology Package. R package version 1.17-1. Available from URL: http://cran.r-project.org/package=vegan

Pappas J. L. \& Stoermer E. F. (1996) Quantitative method for determining a representative algal sample count. f. Phycol. 32, 693-6.

Pollingher U. (1986) Phytoplankton periodicity in a subtropical lake (Lake Kinneret, Israel). Hydrobiologia 138, 127-38.

Rahel F. J. (1990) The hierarchical nature of community persistence: a problem of scale. Am. Nat. 136, 328-44.

Reynolds C. S., Huszar V. L. M., Kruk C., Naselli-Flores L. \& Melo S. (2002) Towards a functional classification of the freshwater phytoplankton. F. Plankton Res. 24, 41728.

Roberts D.W. (2010) labdsv: Ordination and Multivariate Analysis for Ecology. R package version 1.4-1. Available from URL: http://ecology.msu.montana.edu/labdsv/R
Rodrigues L. C., Train S., Bovo-Scomparin V. M., Jati S., Borsalli C. C. J. \& Marengoni E. (2009) Interannual variability of phytoplankton in the main rivers of the Upper Paraná River floodplain, Brazil: influence of upstream reservoirs. Braz. F. Biol. 69, 501-16.

Rodrigues L. M. (2002) Alterações espaciais e temporais de características limnológicas resultantes da transformação rioreservatório na área do reservatório da Usina Hidrelétrica Dona Francisca, RS, Brasil (MSc Thesis). Universidade Federal do Rio Grande do Sul, Porto Alegre.

Scarsbrook M. R. (2002) Persistence and stability of lotic invertebrate communities in New Zealand. Freshw. Biol. 47, 41731.

Soininen J., Tallberg P. \& Horppila J. (2005) Phytoplankton community assembly in a large boreal lake - deterministic pathways or chaotic fluctuations? Freshw. Biol. 50, 207686.

Steele J. H. (1985) A comparison of terrestrial and marine ecological systems. Nature 313, 355-8.

Talling J. F. (1986) The seasonality of phytoplankton in African lakes. Hydrobiologia 138, 139-60.

The R Development Core Team (2009) R: A language and environment for statistical computing. $\mathrm{R}$ Foundation for Statistical Computing, Vienna. ISBN 3-900051-07-0. Available from URL: http://www.R-project.org

Townsend C. R., Hildrew A. G. \& Schofield K. (1987) Persistence of stream invertebrate communities in relation to environmental variability. F. Anim. Ecol. 56, 597613.

Utermöhl H. (1958) Zur Vervollkommnung der quantitativen Phytoplankton-Methodik. Mitt. Int.Ver. Theor. Angew. Limnol. 9, 1-38. 